\title{
Postseismic slip associated with the 2007 Chuetsu-oki, Niigata, Japan, Earthquake ( $M$ 6.8 on 16 July 2007) as inferred from GPS data
}

\author{
Takeshi Iinuma $^{1}$, Yusaku Ohta ${ }^{1}$, Satoshi Miura ${ }^{1}$, Kenji Tachibana ${ }^{1}$, Takeshi Matsushima ${ }^{2}$, Hiroaki Takahashi ${ }^{3}$, \\ Takeshi Sagiya $^{4}$, Takeo Ito ${ }^{4}$, Shin'ichi Miyazaki ${ }^{5}$, Ryosuke Doke ${ }^{6}$, Akira Takeuchi $^{6}$, Kayo Miyao $^{1}$, \\ Akihiko Hirao ${ }^{2}$, Takahiro Maeda ${ }^{3}$, Teruhiro Yamaguchi ${ }^{3}$, Masamitsu Takada $^{3}$, Makiko Iwakuni $^{5}$, \\ Tadafumi Ochi ${ }^{5}$, Irwan Meilano ${ }^{4}$, and Akira Hasegawa ${ }^{1}$ \\ ${ }^{1}$ Research Center for Prediction of Earthquakes and Volcanic Eruptions, Tohoku University, Sendai 980-8578, Japan \\ ${ }^{2}$ Institute of Seismology and Volcanology, Faculty of Sciences, Kyushu University, Shimabara 855-0843, Japan \\ ${ }^{3}$ Institute of Seismology and Volcanology, Hokkaido University, Sapporo 060-0810, Japan \\ ${ }^{4}$ Research Center for Seismology, Volcanology and Disaster Mitigation, Graduate School of Environmental Studies, \\ Nagoya University, Nagoya 464-8602, Japan \\ ${ }^{5}$ Earthquake Research Institute, the University of Tokyo, Tokyo 113-0032, Japan \\ ${ }^{6}$ Department of Earth Sciences, Faculty of Science, University of Toyama, Toyama 930-8350, Japan
}

(Received November 30, 2007; Revised February 4, 2008; Accepted February 26, 2008; Online published November 18, 2008)

Postseismic crustal deformation associated with the 2007 Chuetsu-oki Earthquake, which occurred on 16 July 2007 with a magnitude of 6.8 at the southeastern rim of the Sea of Japan, near the coast of Mid-Niigata Prefecture, Central Japan, are detected by GPS observations. We analyzed continuous GPS data from the sites of the Geographical Survey Institute of Japan (GSI) and another dense temporary network, which we established just after the main shock to reveal spatio-temporal evolution of postseismic slip for 50 days after the main shock by geodetic inversion methods. Four models of faults are configured following Ohta et al. (2008, this issue), and these are optimized based on ABIC (Akaike's Bayesian Information Criterion). The results of the inversion analysis show that the postseismic slip on the faults occurred at a downdip and updip extension of the coseismically slipped portion. The slip in the shallower portion decayed to be negligible within 2 weeks, and the slip in the deeper portion was still large after the slip in the shallower portion had almost terminated.

Key words: Crustal deformation, postseismic slip, GPS, strain concentrated zone, Niigata-Kobe Tectonic Zone.

\section{Introduction}

The Mid Niigata Prefecture, which is called the Chuetsu district, is located in the Niigata-Kobe Tectonic Zone (NKTZ) (Sagiya et al., 2000; Fig. 1), a region of contemporary strain accumulation where the crust is contracting in the NW-SE direction; a similar contraction likely occurs in the Chuetsu district (Iinuma et al., 2005). Historically, several damaging earthquakes have occurred, reflecting this regional stress state in this area. One expample is the Mid Niigata Prefecture Earthquake in 2004 ( $M$ 6.8), which occurred on 23 October 2004 (Fig. 1).

An M 6.8 earthquake occurred on 16 July 2007 in this area. The hypocenter was located about $40 \mathrm{~km}$ northwest of the Mid Niigata Prefecture earthquake in 2004 (Fig. 1). The earthquake was named "the 2007 Chuetsu-oki, Niigata, Japan, Earthquake (COE, hereafter)" by the Japan Meteorological Agency. The focal mechanisms estimated by seismic waveform analyses clarified that reverse faults with strikes directing NE-SW generated this earthquake (Yagi, 2007; Yamanaka, 2007).

A nationwide GPS network "GEONET (GPS Earth Observation Network System)" has been operated by the Ge-

Copyright (c) The Society of Geomagnetism and Earth, Planetary and Space Sciences (SGEPSS); The Seismological Society of Japan; The Volcanological Society of Japan; The Geodetic Society of Japan; The Japanese Society for Planetary Sciences; TERRAPUB. ographical Survey Institute (GSI) of Japan since 1996 (Miyazaki et al., 1997), and continuous GPS data observed by GEONET have revealed several occurrences of postseismic deformation following large earthquakes with high precision in the spatio-temporal domain (e.g. Heki et al., 1997; Miura et al., 2004). However, GEONET is not dense enough to detect smaller deformation rates in the crust, especially postseismic deformation associated with $M \sim 7$ earthquakes, even though it consists of over 1,200 sites with an averaged distance of about $20 \mathrm{~km}$. Therefore, the researchers of the Japanese UNiversity COnsortium of GPS research (JUNCO), to which most of the authors of this paper belong, have performed some permanent and temporary GPS observation to complement the GEONET (e.g. Takahashi et al., 2004; Miura et al., 2006). We also started the construction of a temporary GPS observation network just after the COE in order to observe postseismic deformation precisely (Ohta et al., 2008).

Here, we present the spatio-temporal evolution of the postseismic slip associated with the COE estimated by a geodetic inversion method based on GPS data that is observed by GEONET and our temporary GPS network. We also briefly discuss the implications of the results. 


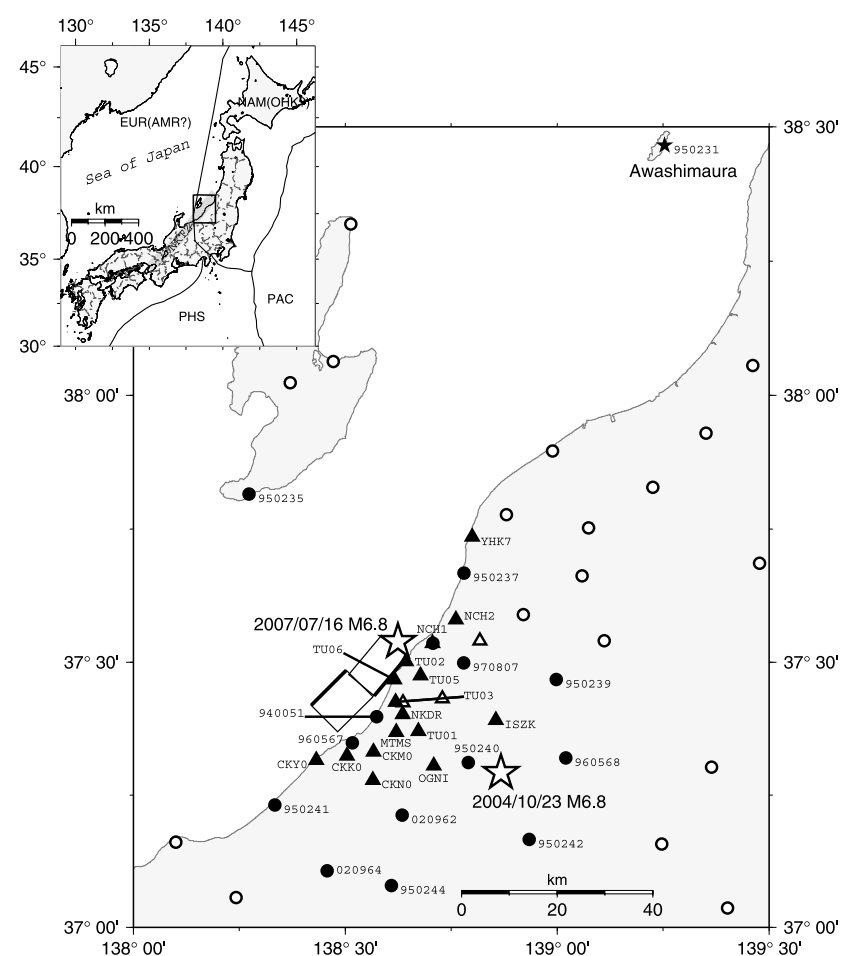

Fig. 1. Map of the study area. Circles and triangles indicate the GPS sites of GEONET and our temporary network, respectively. We used data from the sites represented by solid symbols in the time-dependent inversion analyses. A black star indicates the reference station at Awashimaura (950231). Black rectangles show optimum coseismic faults modeled by Ohta et al. (2008). Bold lines indicate their upper edges. The hypocenters of the main shock and the Mid Niigata Prefecture Earthquake in 2004 are denoted by white stars. EUR, AMR, NAM, OHK, PAC, and PHS indicate Eurasian, Amurian, North American, Okhotsk, Pacific, and Philippine Sea plates, respectively. Gray line indicates Niigata-Kobe Tectonic Zone (NKTZ).

\section{Data and Analysis}

A construction of a temporary GPS network and the analysis of raw GPS data are described in detail by Ohta $\mathrm{et}$ al. (2008). Figure 2 shows time series of displacements at the GPS sites that are used in the inversion analysis. We excluded a GEONET's site 960566 (Izumozaki) because of its remarkable local benchmark motion (Ohta et al., 2008).

We applied a time-dependent inversion method devised by Yagi and Kikuchi (2003) to estimate the spatio-temporal evolution of slip on the fault based on the displacement time series at the GPS sites. The weights of prior constraints on the smoothness of slip distribution in the spatial domain and smoothness of slip rate variation in the temporal domain are optimized by minimizing the Akaike's Bayesian Information Criterion (ABIC) in this inversion method. ABIC was proposed by Akaike (1980) on the basis of the entropy maximization principle (Akaike, 1977) and gives us an objective measure of the goodness of the model; that is, ABIC should be minimum for the best model. We performed a grid search to find the optimum combination of hyper parameters that control the weights of constraint conditions.

We defined four faults in the model based on the result of the coseismic deformation analysis by Ohta et al. (2008). They constructed four models in which two fault planes are aligned in NE-SW direction, and the faults dip to NW or

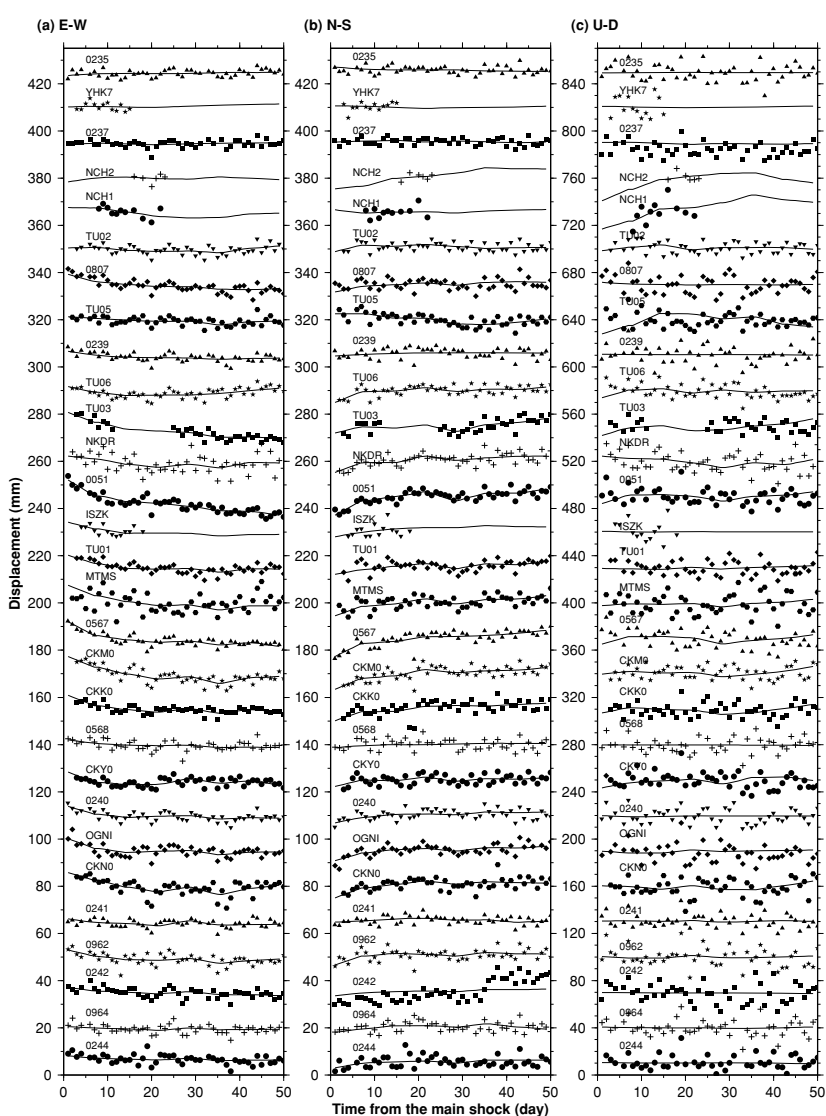

Fig. 2. Displacement time series after the main shock for the GPS sites latitudinally ordered. GEONET's sites are represented by last four digits of their site codes. (a) East-west, (b) north-south, and (c) up-down components. Each symbol represents daily average displacements. Calculated displacement changes from the result of the time dependent inversion analysis for the optimum model at each site are indicated by polygonal line.

SE. The combinations of dipping directions are as follows: both faults dip to NW (Model 1); the northeastern fault dips to NW and the southwestern fault dips to SE (Model 2); the northeastern fault dips to SE and the southwestern fault dips to NW (Model 3); both faults dip to SE (Model 4). Model faults are configured by extending the two coseismic faults to deeper and shallower levels, maintaining a constant dip. The model faults are also extended along the strike of the faults. We estimated slip distributions whose directions are fixed in the directions of the coseismic slip vectors.

\section{Result and Discussion}

Table 1 shows ABIC and released moments from each fault model estimated by the inversion analyses. ABIC is minimized and assures the optimality of the solution for each fault model. It shows that the released moment from the northern fault is not larger than that from the southern fault, reflecting that the displacement time series at the southern sites show larger rates than these at the northern sites (see Figs. 1 and 2). Although the differences in ABIC between the models are not so large, ABICs tell us that the Model 2 is the best. Because of this result and the limitation of space, we only show the result for this model and base our discussion on it.

Figure 3 shows the result of the inversion analysis as the 

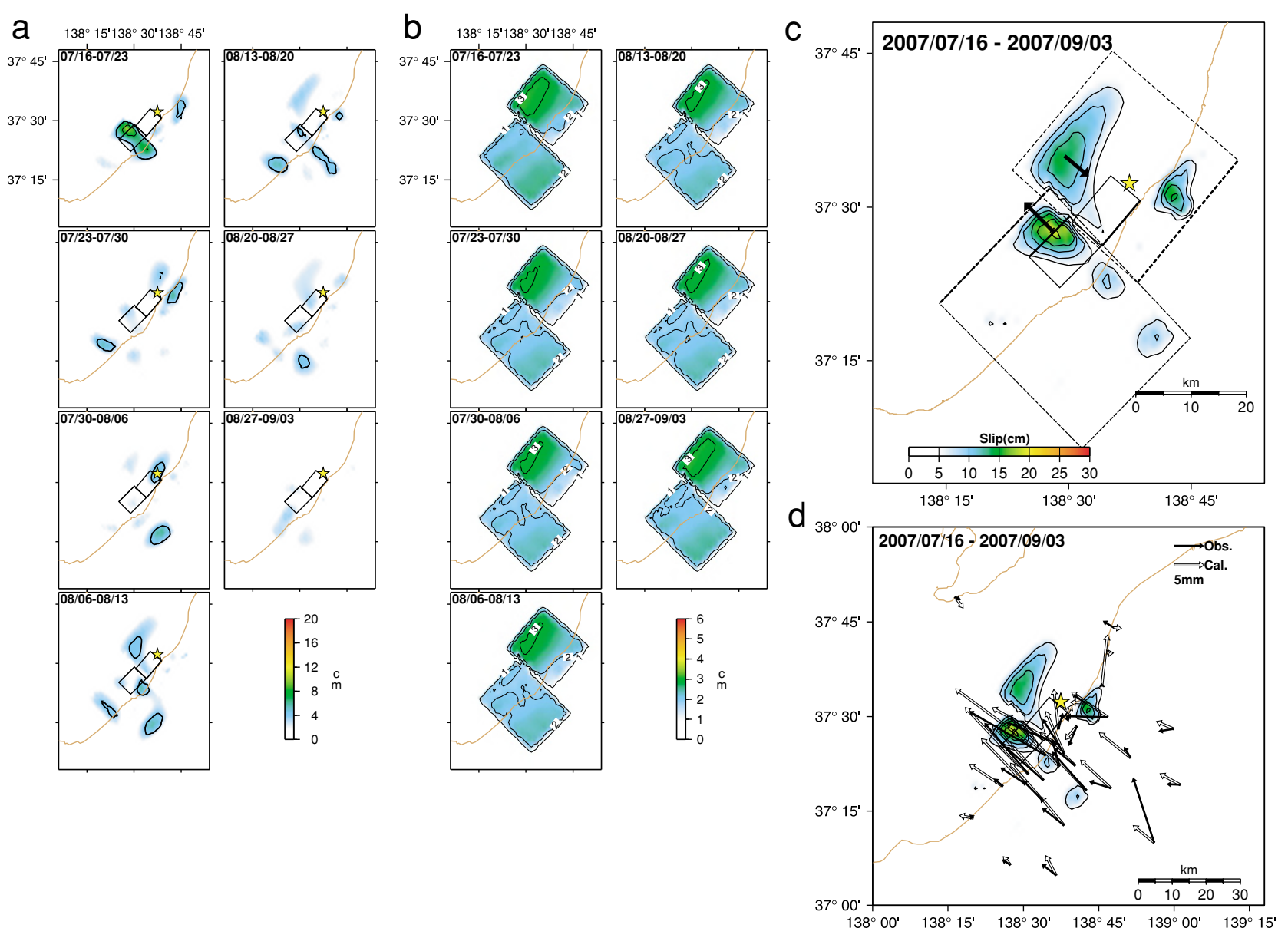

Fig. 3. Results of the time-dependent inversion analysis for the optimum faults model. Black rectangles and brown lines show optimum coseismic faults modeled by Ohta et al. (2008) and coastlines, respectively. (a) Snapshots of slip amount on the faults at 7-day intervals. The contour interval is $4 \mathrm{~cm}$. Thick contours, which correspond to $4 \mathrm{~cm}$, represent the 2- $\sigma$ confidence limit approximately. A star indicates the hypocenter of the main shock. (b) The estimation error corresponding to each snapshot. The contour interval is $1 \mathrm{~cm}$. (c) Cumulative slip distribution for 7 weeks after the main shock. Contour interval is $5 \mathrm{~cm}$. Arrows indicate configured slip direction on each fault. The rectangles edged with dotted lines show the fault surface traces, where bold lines indicate their upper edges. (d) Comparison between observed displacements (black arrows) and calculated ones (white arrows) from the estimated postseismic slip distribution.

Table 1. ABIC and released moments scaled by the Moment Magnitude $\left(M_{\mathrm{w}}\right)$ of the optimum solution for each fault model.

\begin{tabular}{ccccc}
\hline Model & ABIC & \multicolumn{3}{c}{ Released Moment } \\
\cline { 3 - 5 } & & $\begin{array}{c}\text { Northern } \\
\text { fault }\end{array}$ & $\begin{array}{c}\text { Southern } \\
\text { fault }\end{array}$ & Total \\
\hline 1 & 73705.1 & 5.91 & 6.28 & 6.35 \\
2 & 72936.8 & 6.06 & 6.06 & 6.26 \\
3 & 73565.6 & 5.83 & 6.28 & 6.33 \\
4 & 73060.8 & 5.97 & 5.98 & 6.17 \\
\hline
\end{tabular}

series of snapshots for every 7 days with estimation errors, the cumulative slip distributions, and the comparison of the displacements. We can robustly resolve the spatio-temporal evolution of slip amount larger than $4 \mathrm{~cm}$ (adopting a confidence interval of 2- $\sigma$, taking the estimation error into account). The results show the following features with respect to the postseismic slip evolution.

1) The shallow part of the southwestern fault largely slipped immediately after the main shock, and this slip decayed very rapidly in 2 weeks.
2) Slip in the deeper portion of the southwestern fault started after 2 weeks had passed since the main shock.

3) Postseismic slip on the northeastern fault plane started immediately after the main shock, east of the hypocenter, and this slip shifted to deeper part through the northeastern outskirt of the coseismic rupture area.

4) Postseismic slips in both faults mostly terminated before a month had passed.

5) Accumulated postseismic slip distributions indicate that the postseismic slip is concentrated deeper or shallower than the coseismic rupture areas on the both faults.

The fast decay in the shallower portion and the longer duration of slip in the deeper portion are distinctive features of the postseismic slip evolution associated with this earthquake. Almost the same features are observed in the results based on the other models, although the slips in the shallower portion are sometimes unclear. Other several inland earthquakes were accompanied by shallow postseismic slips that are investigated based on geodetic observations. Sagiya et al. (2005) studied the Mid Niigata Prefecture Earthquake in 2004 using GPS data and suggested that 
the source of the postseismic deformation of this earthquake is located at shallower levels than the hypocenters of the main and aftershocks. This idea is also implied by the analysis of InSAR (Ozawa et al., 2005). Nakao et al. (2006) and Hashimoto et al. (2008) detected postseismic slip shallower than the main shock in the 2005 West Off Fukuoka Prefecture Earthquake (M 7.0) and the Noto Hanto Earthquake in 2007 ( $M$ 6.9), respectively. The postseismic slip associated with the COE possibly occurred also in the shallow part, and the results of our inversion analysis support this idea.

Our results indicate the occurrence of postseismic slip in the deeper portion than coseismic ruptured area. The displacement time series at several sites, for instance at 0051, TU03, and TU06, clearly show that the postseismic deformation continued up to the end of analysis period. This deformation can be explained by the postseismic slip in the deeper portions of the coseismic faults as shown in the result of the inversion analyses of this study. Ueda et al. (2001) and Miura et al. (2006) indicated the existence of postseismic slips in deeper portions than focal area of the main and aftershocks associated with the 1978 and 2005 Miyagi-oki earthquakes, respectively. In their result, the deep aseismic slips did not started immediately after the main shock, and their durations are as long as several years and months. Although the target of their research is plate interface in the NE Japan subduction zone, there is a possibility that a similar event may have occurred associated with the COE based on our results of the inversion analysis.

However, it is necessary to consider other possible causes of the variations of the displacement time series, such as annual and semi-annual variation component in the GPS data, visco-elastic relaxation, and poro-elastic rebound.

Viscous behavior of the lower crust or upper mantle causes visco-elastic relaxation. It often occurs after a large earthquake, however, characteristic relaxation time is as long as several years (e.g. Pollitz et al., 2000). For example, Ueda et al. (2003) estimated the relaxation time as 2 years for the postseismic deformation associated with the 1993 Southwest off Hokkaido earthquake, which occurred at the northeastern rim of the Sea of Japan. Therefore, the effect of visco-elastic relaxation is negligible in this study because the length of the total analysis period is less than 2 months.

The origin of the poro-elastic rebound is the movement of the fluid in porous crust due to the stress change that is associated with the earthquake. In most cases, the pattern of the crustal deformation generated by the rebound is opposite to one of the coseismic deformation (e.g. Jónsson et $a l ., 2003)$. Thus, it can not explain our displacement time series because they show almost the same directions of displacement. Coseismic displacement field is shown in Ohta et al. (2008).

Annual and semi-annual variations of GPS data can not be ignored when we analyze GPS time series of several months. However, we do not have data spanning enough time to estimate the seasonal variations because most of sites in the temporary network were constructed just after the main shock, and only 4 months have passed since the earthquake had occurred. We can not eliminate them by some model calculation based on other observations because the origin of this variation is not yet completely un- derstood. Therefore, once enough data have been accumulated, further analyses are necessary to discuss more precisely the effect of annual and semi-annual variations. The examination of the fault models should be performed again in the future once such variations are accounted for.

\section{Summary}

We performed inversion analyses to estimate the aseismic slip distribution and its evolution on the fault in the source area of the 2007 Chuetsu-oki Earthquake based on GPS data. The best model consists of a northwesterly dipping fault on the northeastern side and a southeasterly dipping fault on the southwestern side. The result indicates that postseismic slip started immediately after the main shock in the shallower portions of the coseismic fault and that it had almost terminated within 2 weeks. Deeper portions of the faults may have slipped starting 2 weeks after the main shock.

Acknowledgments. We thank Geographical Survey Institute of Japan for providing their GPS data. We are grateful to the reviewers, Dr. Laura Wallece and Dr. Takuya Nishimura, for their helpful comments and advice. We used the Generic Mapping Tools (Wessel and Smith, 1998) to draw figures. This work was partially supported by Grant-in-Aid for Scientific Research (representative: Prof. T. Iwasaki) of the Ministry of Education, Culture, Sports, Science and Technology.

\section{References}

Akaike, H., On entropy maximization principle, in Application of Statistics edited by P. R. Krishnaiah, pp. 27-41, North-Holland, Amsterdam, 1977.

Akaike, H., Likelihood and the Bayes procedure, in Bayesian Statistics, edited by J. M. Bernardo, M. H. DeGroot, D. V. Lindley, and A. F. M. Smith, pp. 143-166, Univ. Press, Valencia, Spain, 1980.

Hashimoto, M., H. Takahashi, R. Doke, M. Kasahara, A. Takeuchi, K. Onoue, Y. Hoso, Y. Fukushima, K. Nakamura, F. Ohya, R. Honda, M. Ichiyanagi, T. Yamaguchi, T. Maeda, and Y. Hiramatsu, Postseismic displacements following the 2007 Noto peninsula earthquake detected by dense GPS observations, Earth Planets Space, 60(2), 139-144, 2008.

Heki, K., S. Miyazaki, and H. Tsuji, Silent fault slip following an interplate thrust earthquake at the Japan Trench, Nature, 386(6625), 595-598, 1997.

Iinuma, T., T. Kato, and M. Hori, Inversion of GPS velocity and seismicity data to yield changes in stress in the Japanese Islands, Geophys. J. Int., 160(2), 417-434, 2005

Jónsson, S., P. Segall, R. Pedersen, and G. Björnsson, Post-earthquake ground movements correlated to pore-pressure transients, Nature, 424(6945), 179-183, doi:10.1038/nature01776, 2003.

Miura, S., Y. Suwa, A. Hasegawa, and T. Nishimura, The 2003 M 8.0 Tokachi-Oki earthquake-How much has the great event paid back slip debts?, Geophys. Res. Lett., 31(5), L05613, 2004.

Miura, S., T. Iinuma, S. Yui, N. Uchida, T. Sato, K. Tachibana, and A. Hasegawa, Co- and post-seismic slip associated with the 2005 Miyagi-oki earthquake (M7.2) as inferred from GPS data, Earth Planets Space, 58(12), 1567-1572, 2006.

Miyazaki, S., T. Saito, M. Sasaki, Y. Hatanaka, and Y. Iimura, Expansion of GSI's nationwide GPS array, Bull. Geogr. Surv. Inst., 43, 23-34, 1997.

Nakao, S., H. Takahashi, T. Matsushima, Y. Kohno, and M. Ichiyanagi, Postseismic deformation following the 2005 West Off Fukuoka Prefecture Earthquake (M7.0) derived by GPS observation, Earth Planets Space, 58(12), 1617-1620, 2006.

Ohta, Y., S. Miura, T. Iinuma, K. Tachibana, T. Matsushima, H. Takahashi, T. Sagiya, T. Ito, S. Miyazaki, R. Doke, A. Takeuchi, K. Miyao, A. Hirao, T. Maeda, T. Yamaguchi, M. Takada, M. Iwakuni, T. Ochi, I. Meilano, and A. Hasegawa, Coseismic and postseismic deformation related to the 2007 Chuetsu-oki, Niigata Earthquake, Earth Planets Space, 60, this issue, 1081-1086, 2008.

Ozawa, T., S. Nishimura, Y. Wada, and H. Ohkura, Coseismic deformation of the Mid Niigata prefecture Earthquake in 2004 detected by 
RADARSAT/InSAR, Earth Planets Space, 57(5), 423-428, 2005.

Pollitz, F. F., G. Peltzer, and R. Bürgmann, Mobility of continental mantle: Evidence from postseismic geodetic observations following the 1992 Landers earthquake, J. Geophys. Res., 105(B4), 8035-8054, 2000.

Sagiya, T., S. Miyazaki, and T. Tada, Continuous GPS Array and Presentday Crustal Deformation of Japan, Pure Appl. Geophys., 157(11-12), 2303-2322, 2000.

Sagiya, T., M. Ohzono, S. Nishiwaki, Y. Ohta, T. Yamamuro, F. Kimata, and M. Sasaki, Postseismic Deformation Following the 2004 Mid-Niigata Prefecture Earthquake around the Southern Part of the Source Region, Zisin (J. Seismol. Soc. Japan), 58(3), 359-369, 2005 (in Japanese with English abstract).

Takahashi, H., S. Nakao, N. Okazaki, J. Koyama, T. Sagiya, T. Ito, F. Ohya, K. Sato, Y. Fujita, M. Hashimoto, Y. Hoso, T. Kato, T. Iinuma, J. Fukuda, T. Matsushima, Y. Kohno, and M. Kasahara, GPS observation of the first month of postseismic crustal deformation associated with the 2003 Tokachi-oki earthquake ( $M_{\text {JMA }} 8.0$ ), off southeastern Hokkaido, Japan, Earth Planets Space, 56(3), 377-382, 2004.

Ueda, H., M. Ohtake, and H. Ohtake, Afterslip of the plate interface following the 1978 Miyagi-Oki, Japan, earthquake, as revealed from geodetic measurement data, Tectonophys., 338(1), 45-57, 2001.
Ueda, H., M. Ohtake, and H. Sato, Postseismic crustal deformation following the 1993 Hokkaido Nansei-oki earthquake, northern Japan: Evidence for a low-viscosity zone in the uppermost mantle, J. Geophys. Res., 108(B3), 2151, doi:10.1029/2002JB002067, 2003.

Wessel, P. and W. Smith, New, improved version of Generic Mapping Tools released, Trans. Am. Geophys. Union (EOS), 79(47), 579, 1998.

Yamanaka, Y., The Niigataken Chuetsu-Oki Earthquake, 16 July 2007 (M 6.6), NGY seismological notes, 2a, http://www.seis. nagoyau.ac.jp/sanchu/Seismo_Note/2007/NGY2a.html, 2007 (in Japanese).

Yagi, Y. and M. Kikuchi, Partitioning between seismogenic and aseismic slip as highlighted from slow slip events in Hyuga-nada, Japan, Geophys. Res. Lett., 30(2), 1087, doi:10.1029/2002GL015664, 2003.

Yagi, Y., Source process of the Niigataken Chuetsu-Oki Earthquake, 16 July 2007, http://www.geo.tsukuba.ac.jp/press_HP/ yagi/EQ/2007niigata/, 2007 (in Japanese).

T. Iinuma (e-mail: iinuma@aob.geophys.tohoku.ac.jp), Y. Ohta, S. Miura, K. Tachibana, T. Matsushima, H. Takahashi, T. Sagiya, T. Ito, S. Miyazaki, R. Doke, A. Takeuchi, K. Miyao, A. Hirao, T. Maeda, T. Yamaguchi, M. Takada, M. Iwakuni, T. Ochi, I. Meilano, and A. Hasegawa 